\title{
TERRORIST ATTACKS IMPACT ON EMERGENCY DEPARTMENTS
}

\author{
R. Kostadinov*, K. Atliev \\ Department of Epidemiology and Disaster Medicine, Faculty of Public Health, \\ Medical University of Plovdiv, Bulgaria \\ Emergency Department, University Hospital “St. George”, Plovdiv, Bulgaria
}

\begin{abstract}
Successfully performed terrorists' attacks have proved that no country could consider its population secured. What is more, the records are depicting shift into the terrorists tactics - nowadays the desired outcome of the attacks is to inflict as much as possible casualties, as well as an increase in the number of coordinated simultaneous attacks has been recorded. These changes are leading to increased number of casualties requiring emergency medical help provision.

The aim of this study is to analyze the successful terrorist attack impact on the casualties' reception and admittance in the hospitals' emergency departments.

By the means of descriptive and comparative methods the terrorist attacks casualties medical support particularities are analyzed. Cluster analysis is applied in order to group the required changes into the emergency departments work organization.

Expected increased number of patients seeking emergency medical assistance requires enforcement both with human force and medical equipment. Particular considerations are related to the specialized medical support - surgical surge required by the main types of attacks performed. The probabilities of CBRN contamination or terrorists' admittance along with the casualties are demanding changes into the triage place and procedures.

Based on the results of the performed analyses is concluded that contemporary trends in the terrorists' attacks are triggering changes into the emergency departments' work organization and standard operating procedures.
\end{abstract}

Key words: Terrorist attacks, Emergency departments, Triage, Disaster medical support, Surgical surge

\section{INTRODUCTION}

A lot of articles have been published recently in regard to the changes into the terrorists' strategy and tactics. $(1,2)$ These studies are based on the detailed analyses on what and how the terrorists are trying the achieve their goals into last three decades.

In comparison to the terrorists' activities prior 90-s of the twentieth century, the recent acts performed present significant differences into both organization, performance, resources and means. (3) Great majority of experts and researches in their studies highlight the following main characteristics of the contemporary terrorism that are distinguish these activities as a new period of the its development:

\footnotetext{
*Correspondence to: Rostislav Stefanov Kostadinov, 0888631122/0886555310, Department of Epidemiology and Disaster Medicine, Faculty of Public Health, Medical University of Plovdiv, Bulgaria,e-mail: rostikosti@abv.bg
}

1. Regarding the organization, the strict hierarchical structure with organized chain of command, headquarters and established financing, is substituted by a web of semi or fully independent cellular structure with command and control relations hardly to be recognized and traced.

2. 20-th century terrorists' acts were carefully planned and the targets were chosen regarding the particular objective to be reached - assassination of the particular leaders, hijackings and exchange of the hostages for particular, always clearly defined demands, attacks aiming damage on symbolic for the state, party, nation buildings, meetings etc., or for collecting funds for financing. In summary, the attacks were always focused on achieving of the set objective. On opposite, the contemporary attacks are performed with the main objective to inflict as much as possible casualties, 
notwithstanding who will be killed and/or injured.

3. Successfully performed terrorists' attacks in the heart of European Union (Brussels airport), in the cradle of the Western democracy (Paris), in the countries with strict public control and rich societies (Germany, USA, Sweden) have proved that no country could consider its population secured.

4. New trend is the increase in the number of coordinated and/or simultaneous attacks.

5. Terrorists are eager and capable to use weapons of mass destruction. $(4,5,6)$

All these trends changes are leading to increased number of casualties requiring emergency medical help provision.

When there are people requiring emergency medical aid - traumas, injuries, exacerbation of chronic disease they are heading to the hospital emergency departments (HED). In case of the terrorist attack the majority of the casualties will follow the daily pattern - trying to reach the most well-known HED. In great majority of the cases this is the HED of the biggest hospital. The ambulance services will also medically evacuate the most severe injured casualties to the hospital with capabilities to definite treatment of the sustained injury - the biggest hospital. These two flows will very fast overwhelm the capacities of the HED.

\section{THE AIM}

The of this study is to analyze the successful terrorist attack impact on the casualties' reception and admittance in the biggest hospital in the Southern Bulgaria - University Hospital Saint George, Plovdiv.

\section{MATERIALS AND METHODS}

By the means of descriptive and comparative methods the terrorist attacks casualties medical support particularities are analyzed. Cluster analysis is applied in order to group the required changes into the emergency departments work organization.

\section{RESULTS AND DISCUSSION}

The analyzed publications $(7,8)$ regarding the medical support to terrorists' acts are noting the following characteristics of the casualties' medical management:

1. Relatively big number of casualties will appear almost simultaneously, depending on the type of the attack and weather it is one or several coordinated acts.

2. Most of the casualties will sustain multiple or polytraumas.

3. Great majority of light and moderate casualties will be evacuated by their own means and will be not triaged and medically supported in accordance to the standard operating procedures.

4. Great number of people present in the area of attack will seek medical aid without being injured.

5. The number of patients with psychological complains will increase in comparison to the daily routine for the HED.

6. There is risk of casualties' contamination with chemical, radiological or biological agents in case of weapons of mass destructions implementation by the terrorists.

7. A possibility of terrorists' admittance with the other casualties has to be always considered as highly probable.

8. The HED professionals have to be prepared for media and casualties relatives interest and questioning regarding general information or particular questions related to the medical support to the affected.

University Hospital for Active Treatment "Saint George" is the largest multispecialty hospital in Southern Bulgaria. The HED is established for 24 hours' emergency coverage of the patients. The HED includes four wards General Surgery, Internal Diseases, Pediatrics and Orthopedic Surgery along with laboratory and imaginary capabilities.

The routine daily/night shift consists of two specialists in every ward with one anesthesiologist, triage nurses, scrub and anesthesiologist nurses, nurses, medical technicians and six stretcher bearers.

The algorithm of the emergency patient admittance is starting with nurse triaging (with exception of the patients medically evacuated by ambulances) in the first floor - admittance and registration hall. The patient is brought to the second floor in the shock (resuscitation) or particular (internal medicine, surgery, pediatrics or orthopedic surgery) room, depending on triage tag or ambulance physician directive. For enhancing capabilities of these processes a 24-hours video coverage of the both halls is established. After examinations, testing and consultations with the consultants form the respective specialties, all those requiring operations are transported to the operating theatres of the particular clinics, with the exception of those who are operated by the orthopedic surgeons on the same floor. Internal medicine ward is also consulting the patients and depending on the conditions they are transported to the intensive care unit or 
KOSTADINOV R., et al.

respective specialized clinics for continuation of the treatment.

In case of successful terrorist attack, the expected increased number of patients seeking emergency medical assistance requires enforcement both with human force and medical equipment of the HED that could be achieved by calling the physicians on duty from the hospital clinics till arrival of those on call on the duty roster of HED.

Because of the great number of patients with no life-threatening injuries influx is recommendable that triage area out of hospital to be established, where the triage to be performed by experienced physician who will sort two groups - urgent and non-urgent. The primary objective of this out of hospital triage area is not to permit contamination of the hospital, separating and isolating the contaminated casualties, as well as not to admit terrorists (eliminating risk for secondary in-site terrorist's attack).

The increase demand of surgical intervention requires activating the call roster of all surgical departments and blood center. Activation of hospital plan is required in order to liberate beds and to prepare required for the emergency situations drugs, fluids and consumables.

Specific area (out of HED) have to be establish for admitting and treatment of the non-urgent patients.

Third area for public and media relations has to be also established in a manner not to jeopardize the ambulance access and casualties' movement to and from triage area.

\section{CONCLUSION}

Contemporary trends in the terrorists' attacks are triggering changes into the emergency departments' work organization and standard operating procedures.

The process of the triage, casualties flow and responding to the increase number of patients with severe, multiple and poly- traumas and increased demand for surgical interventions and intensive care require special consideration. It is of utmost importance an operational coordination with police to be establish in order to manage the transportation, movement and isolation of the patients and the information exchange.

\section{REFERENCES}

1. Boaz Ganor. Trends in modern international terrorism. In D. Weisburd et al. (eds.), To Protect and To Serve: Policing in an Age of Terrorism, DOI 10.1007/9780-387-73685-3_2, (C) Springer Science + Business Media, LLC 2009

2. David Veness, "Global Trends in Terrorism," The Georgetown Security Studies Review, Special Issue: What the New Administration Needs to Know About Terrorism and Counterterrorism, 20-25, 2017

3. Carlton, D. The West's Road to 9/11, Resisting, Appeasing and Encouraging Terrorism since 1970. Houndmills, Hampshire : Palgrave Macmillan. 2005

4. Gurr, N. \& Cole, B. The New Face of Terrorism, Threats from Weapons of Mass Destruction. London: I.B. Tauris. 2005

5. Voica D.R., Duyan A. Trends and Developments in Contemporary Terrorism (NATO Science for Peace and Security Series E: Human and Societal Dynamics). IOS Press (December 15, 2012)

6. Almogy G, Rivkind AI. Terror in the 21st century: milestones and prospects--part I. Curr Probl Surg.; 44(8):496-554. Aug 2007

7. Sullivan M. K., Donnelly B. Emergency Department Response to Terrorism. Top Emerg Med Vol. 27, No. 1, Lippincott Williams \& Wilkins, Inc pp. 50-77. 2005

8. Halpern P, Tsai M-C, Arnold J, Stok E, Ersoy G: Mass-casualty, terrorist bombings: Implications for emergency department and hospital emergency response (Part II). Prehosp Disast Med;18(3):235-241;2003 